\title{
New velocity map and mass-balance estimate of Mertz Glacier, East Antarctica, derived from Landsat sequential imagery
}

\author{
Etienne BeRTHieR ${ }^{1}$, Bruge RAUP, ${ }^{2}$ Ted SGAMBOS ${ }^{2}$ \\ ${ }^{1}$ OMP-Legos, 18 av. Edouard Belin, 31401 Toulouse Cedex, France \\ E-mail: etienne.berthier@cnes.fr \\ ${ }^{2}$ National Snow and Ice Data Center, CIRES, University of Colorado, Boulder, Colorado 80309-0449, U.S.A.
}

\begin{abstract}
Automatic feature tracking on two Landsat images (acquired in January 2000 and December 2001) generates a complete and accurate velocity field of Mertz Glacier, East Antarctica. This velocity field shows two main tributaries to the ice stream. Between the tributaries, a likely obstruction feature in the bedrock results in a slow-down of the flow. A third Landsat image, acquired in 1989 and combined with the 2000 image, permits the determination of the glacier mean velocity during the 1990s. Although some parts of the Mertz Glacier system show evidence of slight speed increase, we conclude that the Mertz flow speed is constant within our uncertainty $\left(35 \mathrm{~m} \mathrm{a}^{-1}\right)$. Using this complete velocity field, new estimates of the ice discharge flux, $17.8 \mathrm{~km}^{3} \mathrm{a}^{-1}\left(16.4 \mathrm{Gt} \mathrm{a}^{-1}\right)$, and of the basal melting of the tongue, $11 \mathrm{~m} \mathrm{a}^{-1}$ of ice, are given. Our results lead to an apparent imbalance of the drainage basin (ice discharge $3.5 \mathrm{~km}^{3} \mathrm{a}^{-1}$ lower than the accumulation). Considering previous studies in the Mertz Glacier area, we then discuss the uncertainty of this imbalance and the problems with accumulation mapping for this region.
\end{abstract}

\section{INTRODUCTION}

Ice streams are fast-flowing currents of ice feeding ice shelves or reaching the sea at their terminus (Hughes, 1977). These ice streams and their complex extensions inland, detected by balance velocity mapping (Bamber and others, 2000), drain most of the accumulation of the Antarctic ice sheet and consequently are critical for its mass balance: they control the output (or discharge fluxes) of the ice sheet. Mass balance is a key parameter to estimate the evolution of the Antarctic ice sheet and its contribution to sea-level rise.

Fast-moving areas of the ice sheet are, with ice shelves, regions where rapid changes can occur. They are an important system to monitor for effects of climate change. Indeed, a rapid evolution in surface velocity and thickness of a few West Antarctic ice streams has been measured recently. Pine Island Glacier accelerated by $18 \pm 2 \%$ between 1992 and 2000 (Rignot, 2001; Rignot and others, 2002). Altimetry (Wingham and others, 1998) showed that both the Thwaites and Pine Island drainage basins experienced a drop in elevation of $11 \mathrm{~cm} \mathrm{a}^{-1}$ between 1992 and 1996 . Whillans Ice Stream has seen a number of changes in extent, thickness, speed and even direction of flow in its catchment (Bindschadler and Vornberger, 1998; Conway and others, 2002; Joughin and Tulaczyk, 2002).

The continuous interaction of ice streams with the sea also makes them sensitive to changes in sea level and temperature. The fact that the regional pattern of sea-level and temperature changes is far from homogeneous (Cabanes and others, 2001), combined with the evidence that sea temperature has an impact on ice streams (Rignot and Jacobs, 2002), implies that an independent study of the different drainage basins is necessary.
Accurate velocity fields must be calculated to (1) detect any velocity change in the past or in the future, and (2) estimate the discharge fluxes, the basal melting and the mass balance of each individual drainage basin. Different methodologies have been developed to produce velocity fields on these fast-moving glaciers. Repeat visible or near-infrared images of the same area can be used to track the displacement of features moving with the ice (Lucchita and Ferguson, 1986). Development of automatic feature-tracking algorithms (Scambos and others, 1992) significantly increased the accuracy and the efficiency of this approach. A velocity field can also be produced from radar imagery. Using two synthetic aperture radar (SAR) images of the Rutford Ice Stream with short time separation (6 days), Goldstein and others (1993) showed the efficiency of interferometric SAR (InSAR) to accurately measure the one-dimensional displacements of the fast-moving glaciers. Combining ascending and descending passes of the satellite and assuming that ice flows parallel to the surface, one can estimate quasi-three-dimensional velocities (Joughin and others, 1998; Mohr and others, 1998). However, coverage of the ice sheet with ascending and descending InSAR pairs is limited. Recently, "speckle tracking", cross-correlation tracking of SAR coherence speckle, has been combined with SAR interferometry to produce two-dimensional velocity fields (Gray and others, 2001).

The goal of the present study is to determine a complete and accurate velocity field for Mertz Glacier, the derived strain-rate maps, and to compare our estimates of the discharge fluxes, the basal melting and the mass balance with the previous estimates. In the next section, we present a description of Mertz Glacier. Then, in sections 3 and 4, we describe our methodology and the resulting velocity and 


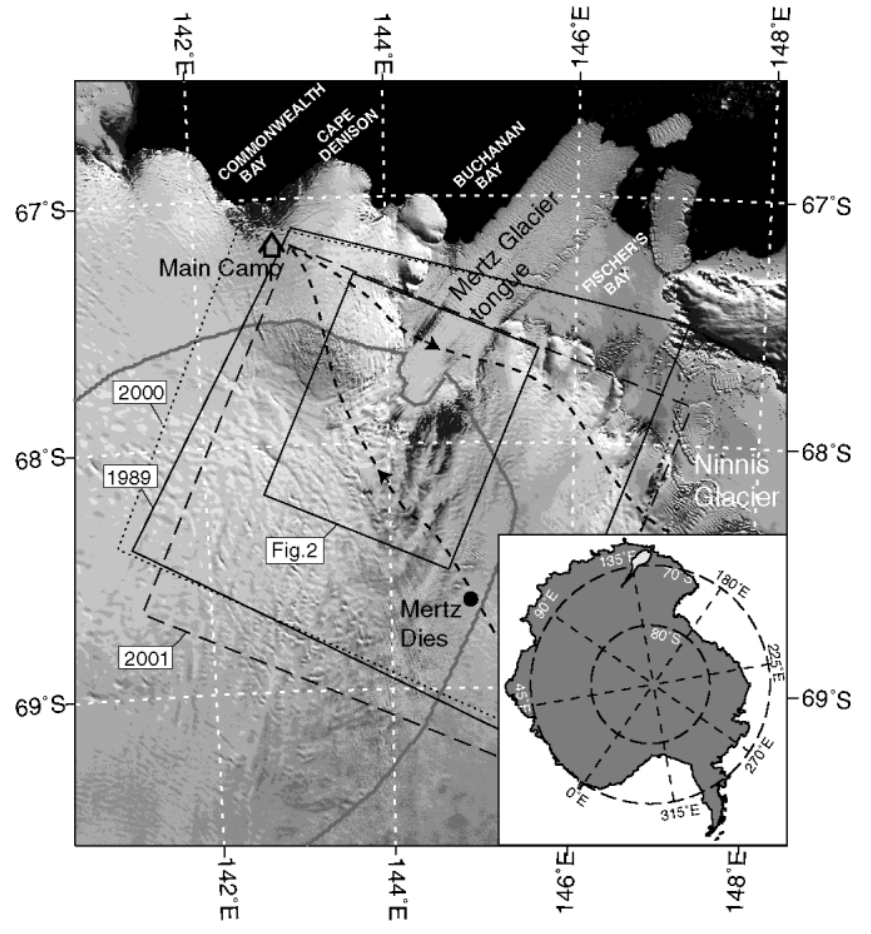

Fig. 1. Location of Mertz Glacier, East Antarctica. The catchment area of the Mertz is shown in white in the inset. On this Moderate Resolution Imaging Spectroradiometer (MODIS) image, we show footprints of the three Landsat scenes and the subscene where velocity measurements were computed. The dashed black line represents the route followed by Mawson and his fellows during their tragic expedition.

strain-rate maps. The fifth section details the calculation of the discharges fluxes, basal melting and mass balance.

\section{STUDY AREA}

Located in King George V Land, East Antarctica (Fig. 1), Mertz Glacier has a prominent ice tongue, extending over $100 \mathrm{~km}$ into the ocean, and drains an area of $83080 \mathrm{~km}^{2}$ (Rignot, 2002), representing $0.8 \%$ of the grounded East Antarctic ice sheet. This glacier owes its name to a tragic expedition led by the Australian explorer Douglas Mawson (Mawson, 1998). Dr X. Mertz, one of Mawson's companions, died in January 1913 during the trek back to Cape Denison, after they had already lost B. Ninnis, the third member of the party, and much of their supplies in a crevasse. To avoid starvation, they were forced to eat their sled dogs. The livers of the dogs, according to recent investigation, concentrated vitamin $\mathrm{A}$ in amounts toxic to humans; vitamin A poisoning was a key factor in Mertz's death.

One of the scientific goals of this early-20th-century expedition was to map the coast and the extent of the Mertz Glacier tongue. Using these data, Wendler and others (1996) calculated that the tongue area increased $>110 \%$ in 80 years. Between 1962 and 1993, it advanced about $26 \mathrm{~km}$, i.e. $840 \mathrm{~m} \mathrm{a}^{-1}$. Since the tongue is floating and in the absence of calving, this value can be considered to be the approximate velocity of the ice when crossing the grounding line plus an additional increment of velocity. Wendler and others (1996) also used a SAR image pair separated by 19 months to determine the short-term velocity of the tongue. A mean value of $1020 \mathrm{~m} \mathrm{a}^{-1}$ was calculated, suggesting that no signif-
Table 1. Landsat images used to study Mertz Glacier

\begin{tabular}{lll}
\hline Acquisition date & \multicolumn{1}{c}{ Sensor } & \multicolumn{1}{c}{ Scene ID } \\
\hline 2 January 1989 & Landsat 5, TM & LT5082108008900210 \\
26 February 2000 & Landsat 7, ETM+ & L71082108_10820000226 \\
13 December 2001 & Landsat 7, ETM+ & LE7082108000134750
\end{tabular}

icant difference exists between the long- and short-term trends, although this study was limited to the tongue area. Wendler and others' surface velocity estimation also allowed a first estimation of the ice discharge flux of Mertz Glacier: $14 \mathrm{~km}^{3} \mathrm{a}^{-1}$ was proposed. A recent study by Rignot (2002) showed that this estimation was performed kilometers downstream of the grounding line. Thus, their discharge flux is probably an underestimate due to basal melting of the floating tongue. Frezzotti and others (1998) showed that the evolution of the length of the tongue is far from linear: from $150 \mathrm{~km}$ in 1912, it reduced to $113 \mathrm{~km}$ in 1956 and increased again to $155 \mathrm{~km}$ in 1996 . They concluded that at least one major calving event occurred between 1912 and 1956.

Rignot (2002) focused on nine glaciers in East Antarctica using InSAR data. A second estimation of the mass balance of Mertz Glacier was made, but poor accuracy of the velocity field (due to a bad relative orientation of the SAR line of sight and the ice flow) increased the uncertainty of the mass balance. The ice-discharge flux of the ice stream was estimated to be $19.8 \mathrm{~km}^{3} \mathrm{a}^{-1}$ at the grounding line, and Rignot proposed a basal melting of $18 \pm 6 \mathrm{~m} \mathrm{a}^{-1}$ of ice just downstream of the grounding line.

\section{DATA AND METHODOLOGY}

\subsection{The three Landsat images and their pre-processing}

Three Landsat images, with a $30 \mathrm{~m}$ pixel size, are used to determine surface velocities (see Table 1). The main velocity field is inferred from a pair of Landsat 7 Enhanced Thematic Mapper Plus (ETM+) images acquired 21.5 months apart: on 26 February 2000 and 13 December 2001. Thus, the main velocity field can be regarded as a 2 year velocity mean centered in mid-January 2001. The last scene, available from the Landsat 5 Thematic Mapper (TM), was acquired 2 January 1989. Correlated with the 2000 image, it gives us the 11 year mean velocity of the ice stream centered in late July 1994. Comparison of the two sets of velocity data could help to detect possible changes of Mertz Glacier over the last decade.

The images are pre-processed to remove the noise and to enhance the small ice features (mostly crevasses) known to move with the flow (Lucchitta and Ferguson, 1986). First, we compute the first principal component of the visible and the near-infrared bands. This step yields low-noise images and enhances the topography. Scan-line striping was removed from the 1989 image using a destriping algorithm, described in Crippen (1989). A spatial filter is then applied to create two sets of images: the low-pass filtered set is used for the co-registration, the high-pass filtered set for the determination of the displacements. The scale of the filter is chosen to separate the small-scale features, moving with the flow, from the fixed long-wavelength features due to the response of ice flowing over topographic features of the bedrock (Paterson, 1994). This is obtained with a scale of the filter 


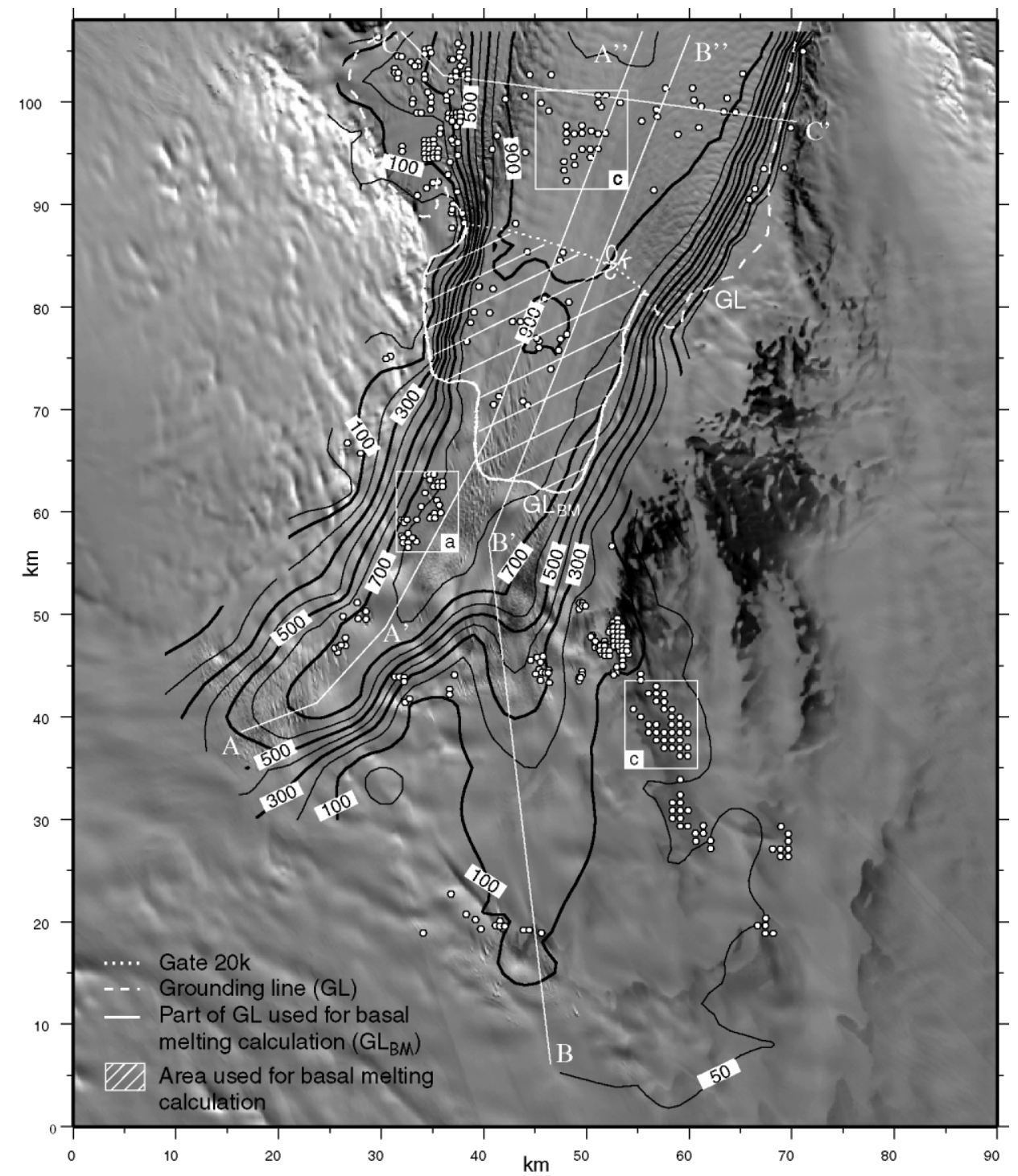

Fig. 2. Contour map of the velocity field of Mertz Glacier deduced from the 2000-2001 pair of images. Contours are drawn every $100 \mathrm{~m} \mathrm{a}^{-1}$ except for the $50 \mathrm{~m} \mathrm{a}^{-1}$ contour. Contours are plotted only where velocity data are available. White circles represent the velocity points deduced from the 1989-2000 pair of images. Ice flows from the lower part to the upper part of the map. White lines locate the three velocity profiles of Figure 3, white boxes (labeled $a, b$ and $c$ ) the subscenes detailed in Figure 4. The grounding line (GL) and the gate $20 \mathrm{~km}$ downstream (20k) are also plotted.

roughly equal to the ice thickness (Budd and Carter, 1971), about $1 \mathrm{~km}$ in the case of Mertz Glacier.

The co-registration of the images is one of the key points of the pre-processing because it will affect the accuracy of the velocities, especially when the time separation is short. First, "visual" co-registration is performed, shifting one of the two images with an offset deduced from comparing the bedrock features in each pair of images. Then, a cross-correlation method (described below) is applied between each low-pass filtered pair. The largest windows are used for this correlation to encompass the maximum of the low-frequency undulations. Using this methodology, Scambos and others (1992) assumed an accuracy of \pm 1 pixel for the co-registration. Our results (mostly the standard deviation) indicate that a \pm 2 pixels accuracy is more reasonable in our study. If $P_{\mathrm{s}}$ is the pixel size $(30 \mathrm{~m})$ and $\Delta t$ the time separation between the two images, this leads to an error for the velocities of $2 P_{\mathrm{s}} / \Delta \mathrm{t}$. This error is referred to below as the "systematic error" and noted $\sigma_{v_{\text {svst }}}$. It equals $\pm 33 \mathrm{ma}^{-1}$ for the 2000-2001 pair and $\pm 5 \mathrm{~m} \mathrm{a}^{-1}$ for the 1989-2000 pair.

\subsection{Determination of the velocity field}

A complete description of the methodology followed to generate the velocity field is found in Scambos and others (1992). Briefly, two high-pass filtered images are used to track the motion of small features by cross-correlating their brightness pattern. Generally, a $32 \times 32$ pixel area is used as a correlation window, but it is changed to $16 \times 16$ when tracking sharp features or to $64 \times 64$ for larger, diffuse ones. The cross-correlation algorithm determines the displacement of the features to sub-pixel precision as well as the strength of the correlation and an estimation of the error in the displacement. The displacement is then assigned to the center of the segment linking the two successive positions of the moving feature.

For the 2000-2001 pair, the 21.5 month time separation results in very little change in surface features and reasonable displacements. Even in the fastest part of the ice stream, the maximum displacement is 60 pixels. Thus, features do not show strong deformation and are easy to track. The accuracy 
of the cross-correlation is estimated to be \pm 0.5 pixel for this pair, which corresponds to $\pm 8 \mathrm{~m} \mathrm{a}^{-1}$. This error, inherent in the cross-correlation, is referred to below as the "random error" and noted $\sigma_{v_{\text {rand }}}$. Computed using Equation (4), the total uncertainty for the 2000-2001 velocities reaches:

$$
\sigma_{v_{00-01}}=\sqrt{\sigma_{v_{\text {rand }}}^{2}+\sigma_{v_{\text {syst }}}^{2}}= \pm 34 \mathrm{ma}^{-1} .
$$

Note that the uncertainty is independent of the absolute value of the velocity. The relative error would be $100 \%$ in an area moving at $34 \mathrm{~m} \mathrm{a}^{-1}$, and only $3.4 \%$ if the ice speed reaches $1000 \mathrm{~m} \mathrm{a}^{-1}$.

For the 1989-2000 pair, the situation is more complicated because of the 11 year time separation. Displacements are much larger, reaching 350 pixels in the center of the ice stream. Moreover, changes due to the wind modification of features and strong distortion of the crevasses make them difficult to track either visually or with the cross-correlation algorithm. In this case, the accuracy is estimated to be around \pm 2 pixels for the displacements. Due to the long time separation, the precision of the velocities remains high: the total uncertainty for the 1989-2000 velocity $\left(\sigma_{v_{89-00}}\right)$ equals $\pm 8 \mathrm{~m} \mathrm{a}^{-1}$.

\section{RESULTS}

\subsection{Velocity field of Mertz Glacier}

The main velocity field is obtained from the 2000-2001 pair, and a contour map is shown in Figure 2. More than 16700 velocity points were used to produce this map. Each of these velocity points results from the cross-correlation algorithm. Automatic selection criteria remove the matches with low correlation strength or large errors. A vector median filter is also applied to remove inconsistent vectors in regions of high density of velocity points (Astola and others, 1990). Eventually, each match is reviewed visually on the computer screen. The contour map is then produced in two steps. Velocity points are resampled to a $2 \mathrm{~km}$ grid, keeping in each gridcell a mean velocity value at the mean location of all the velocity points inside the cell. Then a surface is fitted to all these values using a $1 \mathrm{~km}$ grid size. This velocity dataset is available at http://nsidc.org/data/velmap/.

To better represent the ice-velocity gradients and the shear on the margin of the ice stream, two longitudinal profiles (panels a and b) and one transversal profile (panel c) are shown in Figure 3. To encompass enough velocity points, these profiles are created from the projection of all the velocity measurements within a certain distance of the profile. The swath of the projection must be wide enough to include numerous velocity points and narrow enough to represent well the region where the velocity gradient is high. A width of 100 pixels, i.e. $3 \mathrm{~km}$, is found to be a good compromise. Also in Figure 3, for the 2000-2001 pair, we added the velocities (solid line) and their error envelopes (dotted line) extracted from a high-resolution gridded velocity field.

In Figures 2 and 3, we plot the grounding line determined by Rignot (2002) using tidal movement of the tongue as visible with InSAR. Using an original combination of interferograms from the descending pass, Pötzsch and others (2000) also located the grounding line of Mertz Glacier. The two maps are consistent even if some differences exist. In Figure 2, we located the gate $20 \mathrm{~km}$ downstream of the grounding line (labeled "20k") used to calculate basal melting.
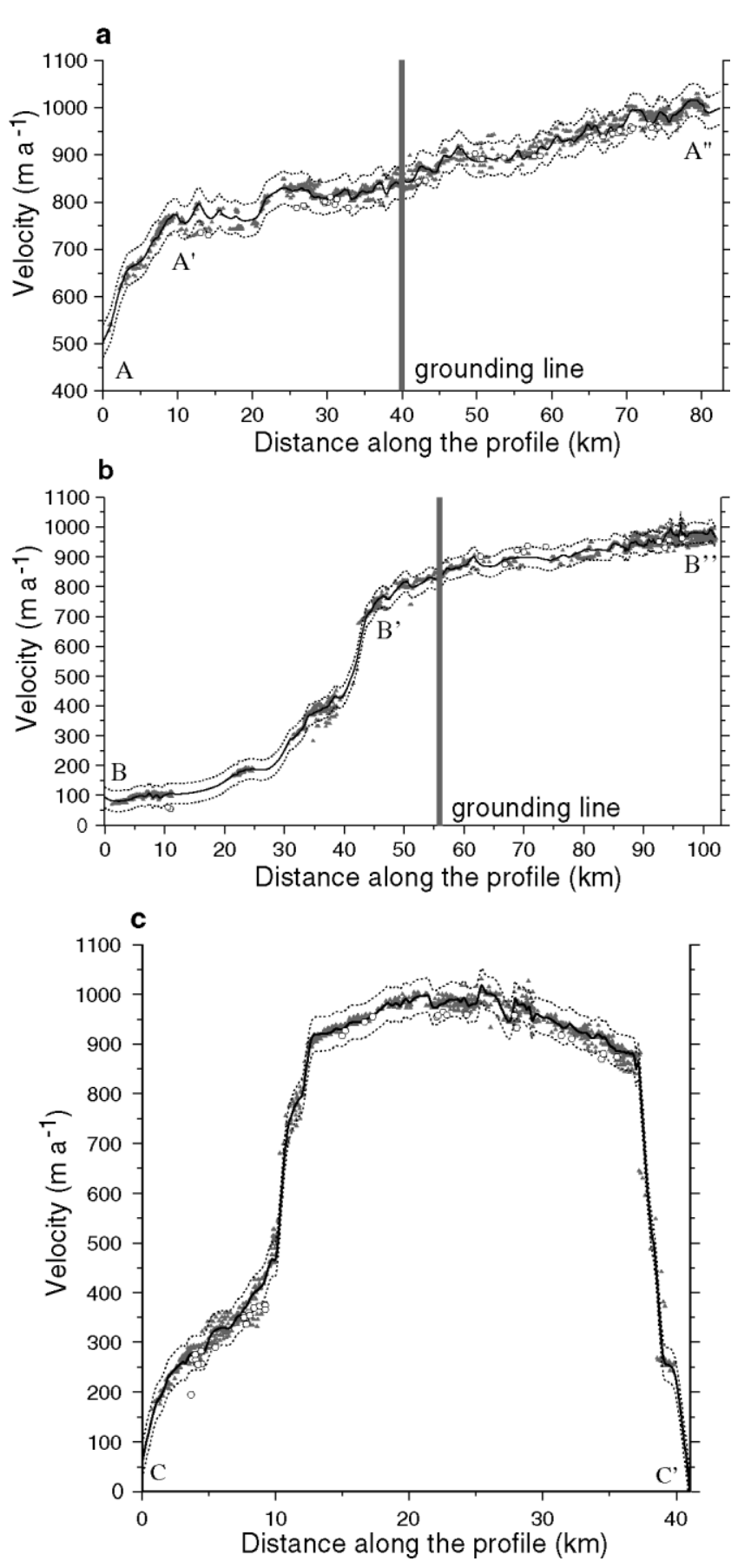

Fig. 3. Longitudinal and transverse velocity profiles of the ice stream: (a) along the main tributary; ( $b$ ) along the secondary tributary; (c) transverse in the downstream part of the ice stream. The gray triangles represent velocity measurements from the 2000-2001 pair, the white circles measurements from the 1989-2000 pair. The black line represents the gridded velocity for the 2000-2001 pair, and the dotted lines the error envelopes obtained by adding and subtracting the uncertainty $\left(34 \mathrm{ma}^{-1}\right)$.

Velocities range from a few $\mathrm{ma}^{-1}$ to $>1000 \mathrm{~m} \mathrm{a}^{-1}$. The contour map shows a well-defined main tributary feeding the ice stream from the lower left corner, i.e. southwest, of the map. In this main tributary, speed increases rapidly from $500 \mathrm{~m} \mathrm{a}^{-1}$ to $750 \mathrm{~m} \mathrm{a}^{-1}$ in $8 \mathrm{~km}$ (A to $\mathrm{A}^{\prime}$ in Fig. 3a). This velocity gradient is mainly due to an increase of the surface slope. In the new topography derived from multiple SAR interferograms by Pötzsch and others (2000), it coincides with altitudes decreasing from $500 \mathrm{~m}$ to $100 \mathrm{~m}$. Below this 


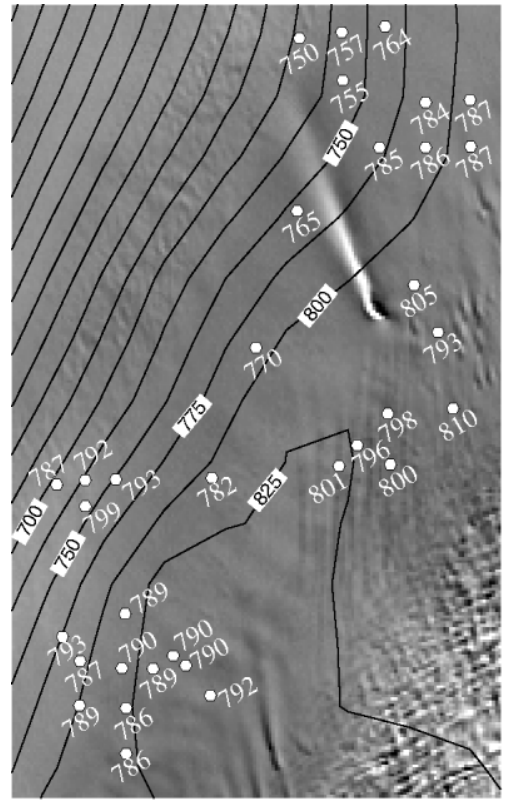

a
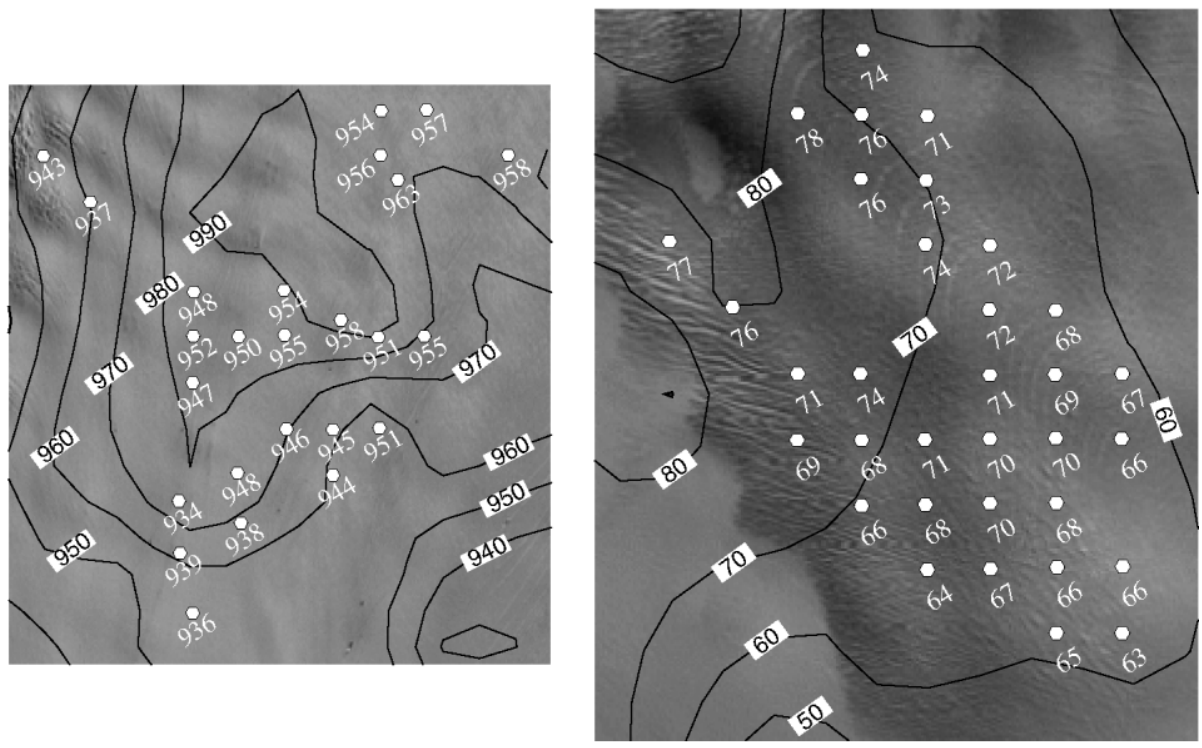

b
C

Fig. 4. Three regions of the ice stream ( $a-c$; see Fig. 2 for locations) where enough matches for the old pair of images (1989-2000, white circles) allow a significant comparison with the velocity contours from the recent pair (2000-2001). The two first subscenes $(a, b)$, along the main tributary, show an increase in velocity of around $30 \mathrm{ma}^{-1}$; the third (c), in a slow-moving part of the glacier, shows no change in velocity.

area, the speed increases still further from $750 \mathrm{ma}^{-1}$ to $1000 \mathrm{~m} \mathrm{a}^{-1}$ in $75 \mathrm{~km}$.

Upstream mapping of the velocity in this main tributary is impossible due to a lack of trackable features. In these regions, where crevasses are absent, cross-correlation of optical imagery reaches its limit. Moreover, with our uncertainty of $\pm 34 \mathrm{ma}^{-1}$, velocity measurements in the catchment area would be highly uncertain.

This southwestern location of the main tributary is in agreement with the catchment area derived from topographic data by Rignot (2002). The drainage basin is mostly located in the western and southwestern part of the ice stream (Fig. 1). In the eastern and southern parts, the ice is drained by the Ninnis Glacier system, the neighboring ice stream to the east.

The velocity map also highlights a second tributary located east of the first one. A longitudinal profile along the tributary $\left(\mathrm{B}-\mathrm{B}^{\prime}\right.$ in Fig. $\left.3 \mathrm{~b}\right)$ also shows a great velocity increase when approaching the grounding line. In this zone, a few kilometers upstream from the grounding line, a $550 \mathrm{~m}$ a ${ }^{1}$ velocity increase is observed in only $17 \mathrm{~km}$. Note that these velocity gradients (and consequently the strain rate determined below) have small errors because they result from relative differences in velocity: the systematic error due to the misfit in the co-registration vanishes; only the random error inherent in the automatic feature tracking remains.

\subsection{Comparison with the $1989-2000$ velocities}

The second pair of images (1989 and 2000) does not produce a complete velocity field: surface features were greatly deformed, so matches are sparse and many of them unreliable. A total of 433 displacement vectors is obtained: not enough to create a reasonable velocity contour map for the whole ice stream. However, in a few regions where the density and quality of the matches are good enough, we can make a comparison with the 2000-2001 velocities. Given the uncertainty in the two datasets, a change in velocity is significant if greater than $\sqrt{\sigma_{v_{00-01}}^{2}+\sigma_{v_{89-00}}^{2}}$, i.e. $35 \mathrm{~m} \mathrm{a}^{-1}$. Thus, even for the fastest part of the glacier the change in velocity must be $>3.5 \%$ to be detectable.

On the longitudinal profile $A-A^{\prime}-A^{\prime \prime}$ and the transverse profile $C-C^{\prime}$ in Figure 3, we observe that most of the 19892000 velocity points are similar in magnitude to the slowest points for the 2000-2001 pair but not different enough to conclude that a major change in the flow speed occurred. Our plot of the velocity profile, i.e. a projection of all the velocity points within a certain distance of the profile, affects the quality of the comparison. It artificially creates a noise in the velocity due to the spatial variation of the velocity within this distance.

Comparing directly the velocities in a few regions is more precise: three regions are located in Figure 2 and are shown in more detail in Figure 4. On these regions, we plotted the velocity contours for the 2000-2001 pair and wrote the velocity values obtained from the 1989-2000 pair. For the two subscenes located along the main flow (Fig. $4 \mathrm{a}$ and b), a consistent velocity change of $30 \mathrm{~m} \mathrm{a}^{-1}$ is observed. This change is under our sensitivity limit of about $35 \mathrm{~m} \mathrm{a}^{-1}$. However, when looking at the third subscene located in a region of slow-moving ice (Fig. 4c), we can see that this sensitivity limit may be overestimated: the two sets of velocities are in good agreement and differ only by $10 \mathrm{~m} \mathrm{a}^{-1}$ in the worst case. This observation holds for all the slow-moving areas. Thus, the $35 \mathrm{~m} \mathrm{a}^{-1}$ value (proved above to be independent of the speed) is quite conservative.

We calculated the mean difference between the two sets of velocities. Where measurements are available for the oldest pair, we extracted from the gridded dataset the velocities for the 2000-2001 pair. The mean velocity increase reaches $15 \mathrm{~m} \mathrm{a}^{-1}$, but the standard deviation (rms) of this difference $\left(45 \mathrm{~m} \mathrm{a}^{-1}\right)$ reflects its large spatial variability and the uncertainties.

The Mertz ice stream may have experienced a slight increase in speed during the last decade, but we cannot prove it, so we conclude that the flow of Mertz Glacier is 
a

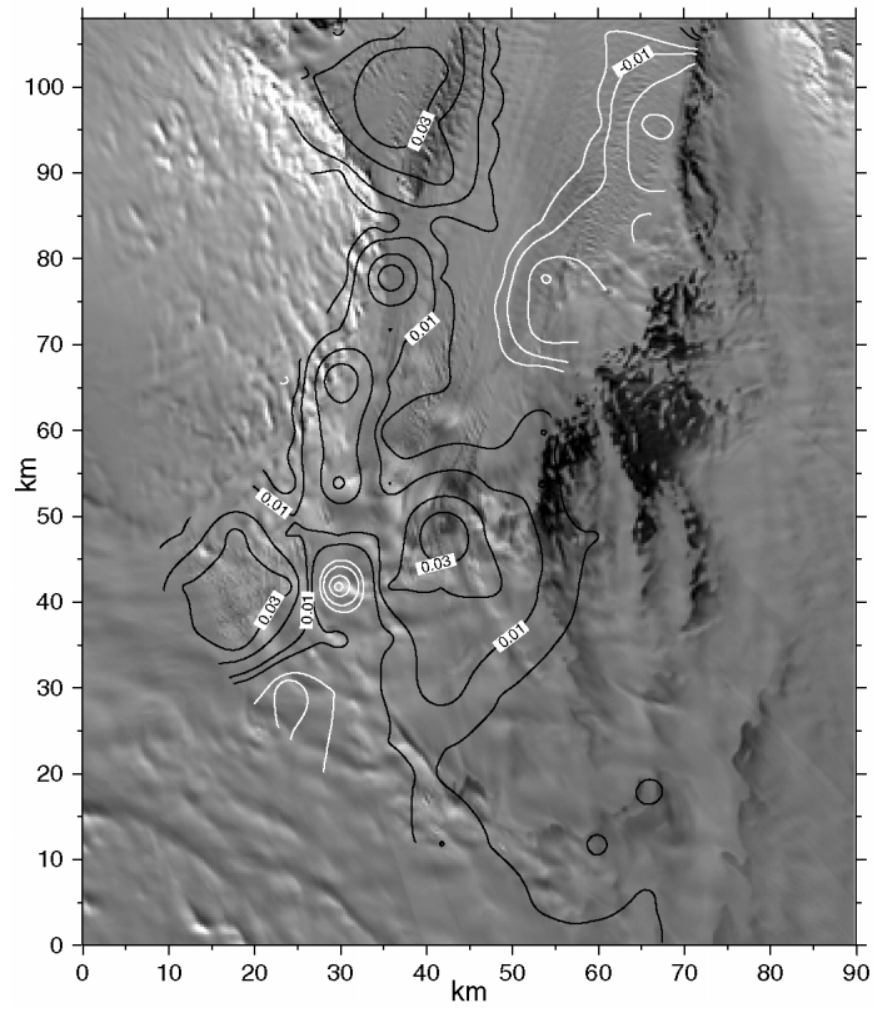

b

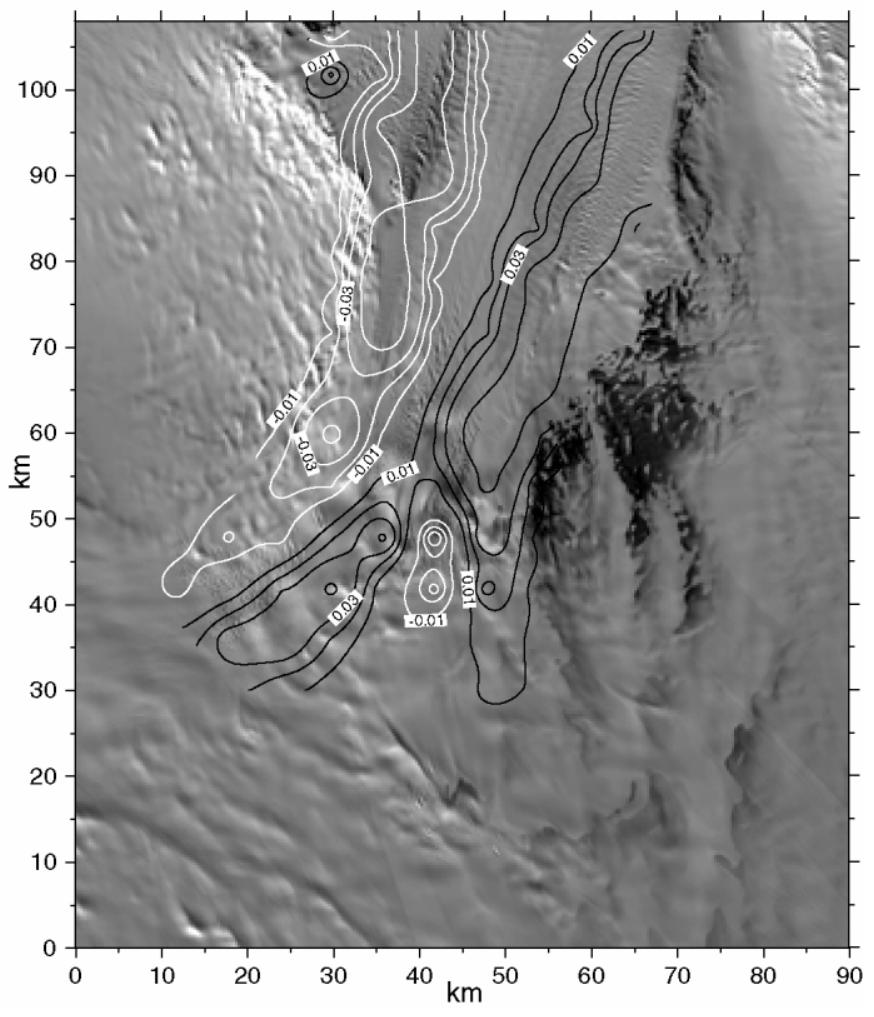

Fig. 5. Strain-rate maps of Mertz Glacier deduced from the 2000-2001 velocity field: (a) the longitudinal strain rate and (b) the shear strain rate.

stationary within our uncertainty. The main limitation is the lack of velocity measurements for the old pair, which prevents us from carrying out a statistical study. A velocity change, if existing, could be better detected with a supplementary image from 1991 or 1992 . Thus, we would produce a complete velocity field for the early 1990s and increase the time separation between the two pairs.

\subsection{Strain rate of the ice stream}

In section 4.1, we touched on the topic of longitudinal strain rate. A velocity increase of $250 \mathrm{~m} \mathrm{a}^{-1}$ in $8 \mathrm{~km}$ along the main flow is similar to a longitudinal strain rate of $0.03 \mathrm{a}^{-1}$. This value is in good agreement with the longitudinal strain-rate map (Fig. 5a). This map was produced using the method described in Nye (1959). This calculation includes a rotation to a local coordinate system parallel ( $x$ axis) and perpendicular $(y$ axis $)$ to the flow direction. Starting from a $1 \mathrm{~km}$ gridded velocity field, we calculated the longitudinal, transverse and shear strain rates using the equations shown in the appendix of Bindschadler and others (1996). These results were then resampled to a $6 \mathrm{~km}$ grid, a scale which proved to be a good compromise between enhancing the signal-tonoise ratio (by filtering the small-scale dynamics effect) and preserving the significant spatial features.

The longitudinal strain-rate map (Fig. 5a) underscores the two main tributaries of the ice stream where a significant increase in velocity creates a positive strain rate $\left(>0.03 \mathrm{a}^{-1}\right)$, i.e. a horizontal stretching. An increase in the density of crevasses with a direction perpendicular to the flow can be observed in these regions. Between the two tributaries a region of negative longitudinal strain rate reflects the effects of a probable obstruction feature in the bedrock. The flow slows down and compression appears upstream of this feature. After crossing the grounding line, the central part of the ice stream experiences lower longitudinal strain rate than the margins. For the whole ice stream, a positive mean longitudinal strain rate $\left(0.6 \times 10^{-3} \mathrm{a}^{-1}\right)$ shows that a horizontal stretching regime prevails. The margins are affected by a large shear strain rate exceeding $0.04 \mathrm{a}^{-1}$ (Fig. 5b). The ice stream is divided into two symmetric regions affected by a shear of similar amplitude but opposite signs. This pattern underscores the highly symmetric flow in Mertz Glacier. The transverse strain rate (not shown here) is generally opposite in sign to the longitudinal strain rate.

The vertical strain rate, $\dot{\epsilon}_{z}$, can be obtained from mass continuity if density is constant:

$$
\dot{\epsilon}_{z}=-\left(\dot{\epsilon_{x}}+\dot{\epsilon_{y}}\right)
$$

where $\dot{\epsilon_{x}}$ and $\dot{\epsilon_{y}}$ are the longitudinal and transverse strain rates. The values of the vertical strain rate are mainly negative. A mean value of $-0.7 \times 10^{-3} \mathrm{a}^{-1}$ for the whole grounded ice stream is the result of the thinning of the ice while flowing to the sea (Bindschadler and others, 1996).

\section{MASS BALANGE OF MERTZ GLAGIER}

\subsection{Discharge fluxes}

Obtaining accurate and well-distributed velocity measurements allows the calculation of the discharge fluxes of the ice stream at different "gates" transverse to the flow and crossing the whole ice stream. Each gate is broken into a number of small segments or "individual gates", through each of which the discharge flux is calculated and summed. The number of gates must be high enough to take into account each change in the magnitude or the direction of the velocity. The mass flux through a given gate, $\Phi_{\text {gate }}$, is cal- 
culated according to:

$$
\Phi_{\text {gate }}=\sum_{i} v_{\perp i} H_{i} \delta w_{i}
$$

where $v_{\perp i}$ is the velocity component perpendicular to the $i$ th segment, $H_{i}$ the mean ice thickness of the $i$ th segment, and $\delta w_{i}$ the width of the $i$ th segment.

For the ice thickness, due to the lack of reliable data in the region of Mertz Glacier (the BEDMAP database includes only three points over the Mertz Glacier tongue), we used the assumption proposed by Rignot (2002) of hydrostatic equilibrium of the floating part of the ice stream. Following Rignot (2002), the ice thickness is deduced from the European Remote-sensing Satellite (ERS) digital elevation model (DEM) by multiplying the elevation by 8.05 . This factor includes both the hydrostatic equilibrium of ice floating over sea water and an offset in geoidal height. Restricted to this assumption, we were only able to calculate discharge fluxes downstream of the grounding line. According to Rignot (2002), the uncertainty of these estimates of ice thickness, $\sigma_{H}$, can be considered as a constant equal to $100 \mathrm{~m}$.

Another key assumption in Equation (3) is constant velocity with depth. Bindschadler and others (1996) showed that this is already a good approximation for the grounded ice stream. For the floating ice, for which no basal drag is present, the bottom of the ice is a free surface and this assumption is all the more realistic.

At the grounding line of Mertz Glacier (noted GL in Fig. 2), we calculated an ice discharge flux of $17.8 \mathrm{~km}^{3} \mathrm{a}^{-1}$.

The uncertainty of this value has to be calculated carefully. As detailed previously, the uncertainty for the main velocity field, $\sigma_{v_{00-01}}$ is $34 \mathrm{~m} \mathrm{a}^{-1}$. This is also the uncertainty of the velocity perpendicular to each segment: in the worst case, this velocity error will be perpendicular to the segment. We assume that the uncertainty of the width of each gate is negligible, supposing that the pixel size of $30 \mathrm{~m}$ provided by Landsat is accurate. The uncertainty is calculated using the following formula extracted from Bevington (1969). If $\Phi$ is our final result, composed of a functional relation $f$ between independent parameters $x, y, z, \ldots$ and if $\sigma_{x}, \sigma_{y}, \sigma_{z}, \ldots$ are the uncertainties in $x, y, z, \ldots$ and are uncorrelated, then the uncertainty in $\Phi$ is:

$$
\sigma_{\Phi}^{2}=\sigma_{x}^{2}\left(\frac{\partial f}{\partial x}\right)^{2}+\sigma_{y}^{2}\left(\frac{\partial f}{\partial y}\right)^{2}+\sigma_{z}^{2}\left(\frac{\partial f}{\partial z}\right)^{2}+\ldots
$$

Applying this equation to the discharge fluxes leads to an uncertainty of:

$$
\sigma_{\Phi}^{2}=\sum_{i}\left[\sigma_{v_{00-01}}^{2}\left(H_{i}^{2}+\sigma_{H}^{2}\right) v_{\perp i}^{2}\right] \delta w_{i}^{2}
$$

The uncertainty of the ice discharge flux at the grounding line is $1.2 \mathrm{~km}^{3} \mathrm{a}^{-1}$ and is equally due to the uncertainty of the velocity and of the ice thickness.

\subsection{Basal melting}

As proposed by Rignot (1996), the melting at the base of the floating part of the ice stream can be calculated by using at least two transverse gates. To calculate the basal melting of Mertz Glacier, we used a closed contour including part of the grounding line and another gate located $20 \mathrm{~km}$ downstream (noted $\mathrm{GL}_{\mathcal{B M}}$ and $20 \mathrm{k}$ respectively in Fig. 2). The area delimited by this contour is $375 \mathrm{~km}^{2}$. The basal melting $\dot{\mathcal{B}}$ is calculated by:

$$
\dot{\mathcal{B}}=\frac{\Phi_{\mathrm{GL}_{\mathcal{B M}}}-\Phi_{20 \mathrm{k}}}{\mathcal{S}}+\dot{\mathcal{A}}
$$

where $\Phi_{\mathrm{GL}_{\mathcal{B M}}}$ is the discharge flux $\left(\mathrm{m}^{3} \mathrm{a}^{-1}\right.$ of ice) at (part of) the grounding line, $\Phi_{20 \mathrm{k}}$ the discharge flux $\left(\mathrm{m}^{3} \mathrm{a}^{-1}\right.$ of ice) $20 \mathrm{~km}$ downstream of the grounding line, $\mathcal{S}$ the area $\left(\mathrm{m}^{2}\right)$ between the two gates, and $\dot{\mathcal{A}}$ the accumulation rate $\left(\mathrm{m} \mathrm{a}^{-1}\right.$ of ice) between the two gates.

Note the difference between $\Phi_{\mathrm{GL}_{\mathcal{B M}}}$ and $\Phi_{\mathrm{GL}}: \Phi_{\mathrm{GL}}$ is the discharge flux through the whole grounding line, whereas $\Phi_{\mathrm{GL}_{\mathcal{B M}}}$ is the discharge flux through the part of the grounding line forming a closed contour with the gate $20 \mathrm{~km}$ downstream (see Fig. 2 to visualize this difference). Thus, $\Phi_{\mathrm{GL}_{\mathcal{B M}}}<\Phi_{\mathrm{GL}}$

With $\Phi_{\mathrm{GL}_{\mathcal{B M}}}=16.6 \pm 1.1 \mathrm{~km}^{3} \mathrm{a}^{-1}$ and $\Phi_{20 \mathrm{k}}=12.6 \pm 0.9 \mathrm{~km}^{3} \mathrm{a}^{-1}$ of ice, and an accumulation rate around $0.35 \mathrm{~m} \mathrm{a}^{-1}$ of ice (Vaughan and others, 1999), we estimate the basal melting to be $11 \mathrm{~m} \mathrm{a}^{-1}$ of ice.

Assuming no error in $\mathcal{S}$ and an accumulation accurate at $\pm 0.1 \mathrm{ma}^{-1}\left(\sigma_{\dot{\mathcal{A}}}\right)$, the uncertainty $\sigma_{\dot{\mathcal{B}}}$ of the basal melting is:

$$
\sigma_{\dot{\mathcal{B}}}^{2}=\left(\frac{\sigma_{\Phi_{G L, \mathcal{B} M}}}{\mathcal{S}}\right)^{2}+\left(\frac{\sigma_{\Phi_{20 \mathrm{k}}}}{\mathcal{S}}\right)^{2}+\sigma_{\dot{\mathcal{A}}}^{2}
$$

We estimate $\sigma_{\dot{\mathcal{B}}}$ to be $\pm 4 \mathrm{~m} \mathrm{a}^{-1}$ of ice.

Our basal-melting estimate of $11 \mathrm{ma}^{-1}$ of ice is nearly $40 \%$ lower than the value of $18 \mathrm{~m} \mathrm{a}^{-1}$ of ice calculated by Rignot (2002). This difference is mostly due to our slower flow speed when crossing the grounding line: at the grounding line, the difference between our ice discharge flux $\left(16.6 \pm 1.1 \mathrm{~km}^{3} \mathrm{a}^{-1}\right)$ and that from Rignot (2002) $\left(19.8 \pm 2 \mathrm{~km}^{3} \mathrm{a}^{-1}\right)$ is $3.2 \mathrm{~km}^{3} \mathrm{a}^{-1}$, whereas it is only $0.5 \mathrm{~km}^{3} \mathrm{a}^{-1}$ at the gate $20 \mathrm{~km}$ downstream (12.6 \pm 0.9 vs $\left.13.1 \pm 1 \mathrm{~km}^{3} \mathrm{a}^{-1}\right)$. We demonstrated previously that the flow of Mertz Glacier is nearly constant, and thus we attribute these differences to errors in the velocities of Rignot (2002). These errors could be due to the fact that "both [Ninnis and Mertz] glaciers flow nearly parallel to the satellite track direction" (Rignot, 2002) which affects the accuracy of the InSAR measurement of the ice velocities. Still, basal melting remains the main factor of ablation for the Mertz Glacier tongue. Due to the limited northern extension of the Landsat scenes we used, the calculation could not be extended in the seaward part of the tongue. Our value for the basal melting is only representative of the first kilometers of the Mertz Glacier tongue. Frezzotti and others (2000), studying outlet glaciers from the Dome $\mathrm{C}$ area, showed that basal melting (and freezing rate) can significantly change along the floating tongue.

\subsection{Mass balance}

The mass balance of the drainage basin can then be estimated using the mass budget method as detailed in Rignot (2002). The total input was calculated by Rignot (2002). Using a DEM of Antarctica, the Mertz drainage basin is delimited and has an area of $83080 \mathrm{~km}^{2}$. On this area, the digital accumulation maps of Vaughan and others (1999) and Giovinetto and Zwally (2000) are integrated to estimate the total annual accumulation: $21.3 \mathrm{~km}^{3} \mathrm{a}^{-1}$ of ice. The mean accumulation for the whole catchment area is thus 
$256 \mathrm{~mm} \mathrm{a}^{-1}$ of ice. This is less than the $272 \mathrm{~mm} \mathrm{a}^{-1}$ of ice previously proposed by Wendler and others (1996).

Thus, Mertz Glacier seems not to be in balance, with an annual input $3.5 \mathrm{~km}^{3}$ of ice higher than the output. If existing, such an imbalance would result in a rate of ice thickening of $4.2 \mathrm{~cm} \mathrm{a}^{-1}$ over the catchment area. Using altimeter data from Seasat and ERS-1, Rémy and Legrésy (1998) mapped the changes in the height of the Antarctic ice sheet between 1978 and 1992. The only area showing a significant rise of the surface is located at $70-72^{\circ} \mathrm{S}, 140-150^{\circ} \mathrm{E}$ and includes part of the Mertz drainage basin. The rise (20-25\% of the accumulation rate) is not very different from our imbalance of $3.5 \mathrm{~km}^{3}$ of ice, which represents $16.5 \%$ of the accumulation rate on the Mertz drainage basin.

On the other hand, the map proposed by Wingham and others (1998) does not show any significant elevation change in the catchment area of Mertz Glacier. We are quite confident in our estimation of the velocity at the grounding line. More uncertainties remain in the ice thickness which results from an assumption. We also wonder whether the accumulation rate on the drainage basin is accurate in an area subject to the strongest wind in the world (Wendler and others, 1993) and where blue-ice areas are widespread. In the accumulation-rate map of Vaughan and others (1999), these are assumed to be areas of nil accumulation although they undergo ablation. Despite the assertion by Bintanja and Van den Broeke (1995) that blue-ice areas are "too small to play an important role in the total surface mass balance regime in Antarctica", we believe that, in some catchments such as Mertz, they could be significant. Another uncertainty results from the very coarse grid in the accumulation-rate map of Vaughan and others (1999): the grid spacing of $1^{\circ}$ is probably too coarse to represent the steep gradient in precipitation near the coast. We suspect that the export of snow by wind (Loewe, 1972) is not well taken into account in the accumulation map. The low density of measurements used by Vaughan and others (1999) in the Mertz area could affect the extrapolation process to a gridded dataset of accumulation: the extrapolation of points with less wind erosion to areas of much greater wind erosion (such as the grounding line of Mertz Glacier) could lead to an overestimation of the accumulation rate in those windy areas. If we assume no imbalance for Mertz Glacier, our measurements suggest that the wind could export $16.5 \%$ of the total precipitation on the drainage basin. This is close to the value of $15 \%$ proposed by Wendler and others (1996). Blowing winds not only export snow: they also increase sublimation. Bintanja (1998) quantified this effect using a one-dimensional atmospheric surface layer model based on observations from automatic weather stations on a transect from Dumont d'Urville to Dome C. Extrapolated to the whole of East Antarctica, the model shows that snowdrift sublimation removes $19 \mathrm{~mm} \mathrm{a}^{-1}$ of ice. This represents $7.5 \%$ of the total precipitation on the Mertz drainage basin.

\section{CONGLUSION}

From two Landsat images with a $30 \mathrm{~m}$ ground resolution, automatic feature tracking allows the determination of the velocity map of Mertz Glacier between February 2000 and December 2001, with an accuracy of $34 \mathrm{~m} \mathrm{a}^{-1}$. Mertz Glacier presents a highly symmetric flow, with a strong increase in velocity when reaching the grounding line. An older image, acquired in 1989, permits a few measurements of the mean velocity during the 1990s. Comparing this second velocity dataset with the main velocity field, we conclude that the flow of Mertz Glacier is stationary within our sensitivity limit of $35 \mathrm{ma}^{-1}$. The quality of the main velocity field allows a new assessment of the discharge flux, the basal melting and the mass balance of the drainage basin of Mertz Glacier. The ice discharge flux at the grounding line is $17.8 \pm 1.2 \mathrm{~km}^{3} \mathrm{a}^{-1}$. Comparing with the annual accumulation of $21.3 \mathrm{~km}^{3}$ of ice leads to an imbalance, the input being $20 \%$ higher than the output. From the published studies, it is not clear whether the Mertz Glacier accumulation area experienced any elevation change. Our results agree with the positive imbalance of $20 \%$ observed by Rémy and Legrésy (1998). On the other hand, if we assume (as do Vaughan and others, 1999) that no elevation change occurs in the area, our imbalance could result from errors in the measurements and gridding of the accumulation. In this part of Antarctica, subjected to the strongest winds in the world, the importance of blue ice and negative local net surface balance should be reassessed. Obtaining thickness profiles transverse to the ice stream would also increase the reliability of the discharge fluxes. The basal melting on the floating ice tongue, $11 \pm 4 \mathrm{~m} \mathrm{a}^{-1}$ of ice, is lower than the previous estimate (18 $\pm 6 \mathrm{~m} \mathrm{a}^{-1}$ of ice) by Rignot (2002).

\section{ACKNOWLEDGEMENTS}

The first author would like to thank R. Barry for welcoming him at the U.S. National Snow and Ice Data Center, and the Institut de Recherche pour le Développement, France, for contributing to the funding of the internship. This study was supported by NASA grant NAG5-3438. We thank E. Rignot (Jet Propulsion Laboratory) for providing data on the elevation, accumulation and location of the grounding line of the Mertz area. We sincerely thank M. Frezzotti and an anonymous reviewer, J. Meyssonnier (Scientific Editor) and W. D. Harrison (Chief Editor) for making useful comments on earlier versions of the manuscript. P. Wessel and W. Smith's Generic Mapping Tools software (Wessel and Smith, 1998) illustrated the paper.

\section{REFERENCES}

Astola, J., P. Haavisto and N. Yrjö. 1990. Vector median filter. Proc. IEEE, 78(4), 678-689.

Bamber, J. L., D. G. Vaughan and I. Joughin. 2000. Widespread complex flow in the interior of the Antarctic ice sheet. Science, 287(5456), 1248-1250.

Bevington, P. R. 1969. Data reduction and error analysis for the physical sciences. New York, McGraw-Hill.

Bindschadler, R. and P. Vornberger. 1998. Changes in the West Antarctic ice sheet since 1963 from declassified satellite photography. Science, 279 (5351), 689-692.

Bindschadler, R., P. Vornberger, D. Blankenship, T. Scambos and R. Jacobel. 1996. Surface velocity and mass balance of Ice Streams D and E, West Antarctica. 7. Glaciol., 42(142), 461-475.

Bintanja, R. 1998. The contribution of snowdrift sublimation to the surface mass balance of Antarctica. Ann. Glaciol., 27, 251-259.

Bintanja, R. and M. R. van den Broeke. 1995. The surface energy balance of Antarctic snow and blue ice. 7. Appl. Meteorol., 34(4), 902-926.

Budd, W. F. and D. B. Carter. 1971. An analysis of the relation between the surface and bedrock profiles of ice caps. F. Glaciol., 10(59), 197-209.

Cabanes, C., A. Cazenave and C. Le Provost. 2001. Sea level rise during past 40 years determined from satellite and in situ observations. Science, 294(5543), 840-842.

Conway, H., G. Catania, C. Raymond, T. Scambos, H. Engelhardt and A. Gades. 2002. Switch of flow direction in an Antarctic ice stream. Nature, 419(6906), 465-467. 
Crippen, R. E. 1989. A simple filtering routine for the cosmetic removal of scan-line noise from Landsat TM P-tape imagery. Photogramm. Eng. Remote Sensing, 55(3), 327-331.

Frezzotti, M., A. Cimbelli and J. G. Ferrigno. 1998. Ice-front change and iceberg behaviour along Oates and George V Coasts, Antarctica, 1912-96. Ann. Glaciol., 27, 643-650.

Frezzotti, M., I. E. Tabacco and A. Zirizzotti. 2000. Ice discharge of eastern Dome C drainage area, Antarctica, determined from airborne radar survey and satellite image analysis. F. Glaciol., 46(153), 253-264.

Giovinetto, M. B. and H. J. Zwally. 2000. Spatial distribution of net surface accumulation on the Antarctic ice sheet. Ann. Glaciol., 31, 171-178.

Goldstein, R. M., H. Engelhardt, B. Kamb and R. M. Frolich. 1993. Satellite radar interferometry for monitoring ice sheet motion: application to an Antarctic ice stream. Science, 262(5139), 1525-1530.

Gray, A. L., N. Short, K. E. Mattar and K. C. Jezek. 2001. Velocities and ice flux of the Filchner Ice Shelf and its tributaries determined from speckle tracking interferometry. Can. F. Remote Sensing, 27(3), 193-206.

Hughes, T. 1977. West Antarctic ice streams. Rev. Geophys. Space Phys., 15(1), 1-46.

Joughin, I. and S. Tulaczyk. 2002. Positive mass balance of the Ross ice streams, West Antarctica. Science, 295(5554), 476-480.

Joughin, I. R., R. Kwok and M. A. Fahnestock. 1998. Interferometric estimation of three-dimensional ice-flow using ascending and descending passes. IEEE Trans. Geosci. Remote Sensing, GE-36(1), 25-37.

Loewe, F. 1972. The land of storms. Weather, 27(3), 110-121.

Lucchitta, B. K. and H. M. Ferguson. 1986. Antarctica: measuring glacier velocity from satellite images. Science, 234(4780), 1105-1108.

Mawson, D. 1998. The home of the blizzard, a true story of Antarctic survival. New York, St Martin's Press.

Mohr, J.J., N. Reeh and S. N. Madsen. 1998. Three-dimensional glacial flow and surface elevation measured with radar interferometry. Nature, 391 (6664), 273-276.

Nye, J. F. 1959. A method of determining the strain-rate tensor at the surface of a glacier. 7. Glaciol., 3(25), 409-419.

Paterson, W. S. B. 1994. The physics of glaciers. Third edition. Oxford, etc., Elsevier.
Pötzsch, A., B. Legrésy, W. Korth and R. Dietrich. 2000. Glaciological investigations of Mertz Glacier, East Antarctica, using SAR interferometry and field observations. In ERS-ENVISAT Symposium "Looking down to Earth in the New Millennium", 16-20 October 2000, Gothenburg, Sweden. Proceedings. Noordwijk, European Space Agency, CD-ROM. (ESA SP-461.)

Rémy, F. and B. Legrésy. 1998. Antarctic non-stationary signals derived from Seasat-ERS-1 altimetry comparison. Ann. Glaciol., 27, 81-85.

Rignot, E. 1996. Tidal motion, ice velocity and melt rate of Petermann Gletscher, Greenland, measured from radar interferometry. 7. Glaciol., 42(142), 476-485.

Rignot, E. 2001. Evidence for rapid retreat and mass loss of Thwaites Glacier, West Antarctica. 7. Glaciol., 47(157), 213-222.

Rignot, E. 2002. Mass balance of East Antarctic glaciers and ice shelves from satellite data. Ann. Glaciol., 34, 217-227.

Rignot, E. and S. S. Jacobs. 2002. Rapid bottom melting widespread near Antarctic ice sheet grounding lines. Science, 296(5575), 2020-2023.

Rignot, E., D. G. Vaughan, M. Schmeltz, T. Dupont and D. MacAyeal. 2002. Acceleration of Pine Island and Thwaites Glaciers, West Antarctica. Ann. Glaciol., 34, 189-194.

Scambos, T. A., M. J. Dutkiewicz, J. C. Wilson and R. A. Bindschadler. 1992. Application of image cross-correlation to the measurement of glacier velocity using satellite image data. Remote Sensing Environ., 42(3), 177-186.

Vaughan, D. G., J. L. Bamber, M. B. Giovinetto, J. Russell and A. P. R. Cooper. 1999. Reassessment of net surface mass balance in Antarctica. 7. Climate, 12(4), 933-946.

Wendler, G., J. C. André, P. Pettré, J. Gosink and T. Parish. 1993. Katabatic winds in Adélie coast. In Bromwich, D. H. and C. R. Stearns, eds. Antarctic meteorology and climatology: studies based on automatic weather stations. Washington, DC, American Geophysical Union, 23-46. (Antarctic Research Series 61.)

Wendler, G., K. Ahlnäs and C. S. Lingle. 1996. On Mertz and Ninnis Glaciers, East Antarctica. 7. Glaciol., 42(142), 447-453.

Wessel, P. and W. H. F. Smith. 1998. New, improved version of the Generic Mapping Tools released. Eos, 79(47), 579. (http://gmt.soest.hawaii.edu/.)

Wingham, D. J., A. L. Ridout, R. Scharroo, R. J. Arthern and C. K. Shum 1998. Antarctic elevation change 1992 to 1996. Science, 282(5388), 456-458.

MS received 13 Fanuary 2003 and accepted in revised form 28 July 2003 